\title{
Fostering Resilience for Puerto Rican College Students in Transition After Hurricane Maria
}

\author{
Dr. Leslie Jo Shelton, Assistant Professor of Higher Education, HIED \\ M.Ed. Program Coordinator, University of Arkansas
}

Charles J. Thompson, M. Ed., Doctoral Student, Graduate Assistant, Higher Education, University of Arkansas

The primary purpose of this study is to explore the impact of 2017 Hurricane Maria on Puerto Rican college students directly affected by the storm, including how institutions of higher education fostered resilience for displaced and non-displaced students transitioning to navigating college after the storm. Findings indicate that participants were greatly affected by Hurricane Maria, and community ties, along with logistical challenges, influenced their college experiences after the storm. Participants shared suggestions for campus educators to better serve students in transition after natural disasters, indicating that providing swift, clear responses to crises, including proactive outreach, are key institutional actions in addition to creating community and demonstrating care for individual student circumstances.

Keywords: hurricane, Puerto Rico, college students, resilience, transition 
The 2017 hurricane season resulted in a high death toll and costly damages (Johnson, 2017), and institutions of higher education in the U.S., U.S. territories, and nearby countries were directly impacted by the 2017 Hurricanes Harvey, Irma, and Maria. Hurricane Maria was particularly devastating to life and infrastructure, with a death toll estimated at 2,975 people (Santiago \& Schoicet, 2018). It is important to identify the impact natural disasters have upon students so that higher education/student affairs (HESA) educators can learn how to best support this student population during times of transition due to crises. Hurricanes "are among the deadliest and most destructive natural disasters" and "recent climate modeling studies suggest increases in the future number of intense tropical cyclones" (Patricola \& Wehner, 2018, p. 339). As such, institutions of higher education will continue facing this issue as we strive to support students through hurricane and other natural disaster-related crises.

The current study examines the stories of three Puerto Rican college students directly impacted by Hurricane Maria who faced challenges in the transition to navigating higher education after the storm. To understand how student affairs educators can create supportive conditions after such crises, the current study explores how these students demonstrated resilience in navigating college after the storm. Although participants shared contextual information related to their home institutions in Puerto Rico, the current study purpose evolved to focus on educational practice at institutions in the continental U.S. which may host relocated students. Findings indicate that participants were greatly impacted by Hurricane Maria, and community ties, along with logistical challenges, impacted their college trajectories related to deciding to stay or to relocate to the contiguous U.S. to continue in college after the storm. Participants shared suggestions for campus educators to better serve students impacted by natural disasters, indicating that providing swift, clear responses to crises, including proactive outreach, are key institutional actions in addition to creating community and demonstrating care for individual student circumstances. 


\section{Literature Review}

In looking at literature for this topic, we examined research related to college students' experiences with natural disasters and campus crisis management following natural disasters.

\section{College Students' Experiences with Natural Disasters}

There is limited research on college students' experiences with natural disasters. But the current research on students affected by natural disasters tends to focus upon psychological effects, such as posttraumatic stress, retention and motivation, or student disaster preparedness.

Psychological effects. Among general populations, posttraumatic stress disorder (PTSD) is prevalent following natural disasters, and, as Bromet et al. (2017) found, it is highly significantly correlated with high education levels, serious injury and/or death of someone close, displacement, and pre-existing negative conditions like mental disorders.

Posttraumatic stress. Understanding the psychological effects natural disasters have on students is a key thread in natural disaster research. In her longitudinal, mixed-methods, single-campus study, Waters (2016) found that her participants, primarily black women community college students, faced similar outcomes due to stressors brought on by Hurricane Katrina; however, those who had more resources, such as owning a car, having more money, or having greater social support, tended to face fewer stressors. No matter the participants' background, those who directly faced trauma during the hurricane were much more likely to develop PTSD. Waters (2016) found that of those who were displaced by the hurricane, many chose not to return to their home in New Orleans, and by 2010 , felt they did not have their lives "back on track" (para. 29). These findings were shared by Davis and his colleagues (2010) who found that displaced college students were more likely to develop stress, PTSD, and depression due to the trauma associated with Hurricane Katrina.

Retention and motivation. In their quantitative study at a single HBCU, Phillips and Herlihy (2009) looked at factors that motivated students to continue their studies following Hurricane Katrina. Among the reasons for returning, their survey participants chose to return due to 
a strong desire to earn a degree, improve themselves, meet their career and educational goals, and attend an HBCU. Interestingly, motivations surrounding campus environment did not play a role in their decision to continue at the institution. In examining retention rates of displaced students at host universities, Coco (2015) interviewed administrators from universities that accepted students displaced by the hurricanes. Among his findings were that a majority of universities offered support such as relaxing admissions requirements or offering counseling or therapy. Many administrators reported that the displaced students were treated like any other student, and that they expected the displaced students to return to their universities within one year. Coco (2015) pointed out that most institutions that accepted displaced students returned to their original enrollment numbers within two years of Hurricane Katrina. Administrators cited that students were not retained due to lack of finances or wanting to be with family; however, they believed students who were retained chose to stay due to newly formed friendships.

Student disaster preparedness. A number of studies show that college students have a startling lack of preparedness for natural disasters. For example, Simms, Kusenbach, and Tobin (2013) found that approximately $20 \%$ of college students do not sign up for emergency, disaster-related text notifications from their universities, and only $8 \%$ of students have made plans in the instance that they would experience a hurricane. Moreover, most students do not have supplies prepared in the case of a natural disaster (Lovekamp \& McMahon, 2011), which is partly due to students believing that their chances of facing a type of disaster on campus are low (Simms et al., 2013). These findings are echoed by Davis, Weber, Schulenberg, and Green (2019) who likewise found that students lack both preparedness and concern over the possibility of experiencing disasters. Lee and Lee (2019) found that college students' perceptions of response strategies and information regarding disasters can influence students' experiences with anxiety and depression, thus it is important to not only improve students' preparedness for but also their knowledge of natural disasters. 


\section{Campus Crisis Management}

Shaw (2016a, 2016b, 2018) examined campus climate management following hurricanes affecting the Gulf Coast. In a joint case study, Shaw (2016a) followed two universities' responses to natural disasters and how they affected organizational change. She split her findings into three tiers of change categories: 1) campus facilities; 2) systems of operations; and 3) employee responsibilities. When discussing campus facilities, she found that both campuses had to endure multiple projects of either renovation or rebuilding, and as a result, one campus hosted FEMA trailers which were eventually replaced with a new residence hall. Shaw also found that in terms of systems operations, both campuses updated crisis management plans to be prepared for future hurricanes, had changes to IT systems, and even had changes to degree programs and course offerings. Finally, both campuses saw changes in employee responsibilities. Though employee issues were specific to the individual's circumstances, both campuses saw a reduction in staff, shifts in responsibilities, and more. Building upon this work, Shaw (2016b) examined pathways to reaching institutional equilibrium, which she defined as the campus both reopening and continuing operations. Shaw built a framework which had two main goals to assist institutions in establishing equilibrium: shortening the length of the punctuation period, and locating and accessing helpful resources. Shaw (2016b) argued that though universities may reach equilibrium, they still may be working towards complete recovery, as the two are not necessarily dependent upon one another. Finally, Shaw (2018) examined how a HESA graduate preparation program trained future student affairs professionals in a single crisis management course that was designed to be cumulative, sequential, and collaborative by simulating real crises and requiring quick decision-making and collaborative discussion. Shaw (2018) found that students reported that they successfully gained skills that would be required in crisis management through enrollment in the course.

The current literature on college students experiencing natural disasters shows a number of things. First, students and campus administrations are ill-prepared for experiencing natural disasters. 
Second, there is a need to understand that college students are likely to experience posttraumatic stress after natural disasters. Finally, fostering resilience can be an important strategy for supporting individuals who experience a natural disaster. There is an opportunity to provide scholarship examining ways to foster resilience among college students who experience natural disasters. The current study contributes to the literature by addressing ways to help build the capacity for resiliency following a natural disaster.

\section{Theoretical Framework}

This study was guided by resilience theory, including educational resilience theory and recent scholarship on resilience as a practice, not an inherent trait, that recognizes agency and comes from an affirmative standpoint (Nicolazzo, 2017). Collins (2009) explained one common definition of resilience theory as the ability to adapt to risk factors by using protective factors, which requires actively handling stress and challenges. Brown (2010) described the five main factors of resilient people, including being resourceful with good problem-solving skills, being likely to seek help, believing they can manage feelings to cope, having social support available to them, and being connected to others such as family or friends. Higher education researchers Pérez, Espinoza, Ramos, Coronado, and Cortes (2009) explained that resilience theory "is focused more on strengths rather than deficits and understanding healthy development in spite of high-risk exposure. Personality characteristics and environmental social resources are thought to moderate the negative effects of stress and promote positive outcomes despite risks" (p. 6). A specific branch of resilience theory called educational resilience theory "commonly refers to the ability to succeed in school despite difficult or adverse circumstances, often through the presence or development of protective factors" (Waxman, Gray, \& Padron, 2003).

Our framework highlights both the intrinsic and extrinsic factors associated with resilience. Resilience scholars have noted the importance of intrinsic, or personal protective factors, such as social competence, problem-solving skills, autonomy, a sense of purpose and future, 
self-efficacy, effective coping behaviors, and internal locus of control (Bean \& Eaton, 2001; Benard, 1993; Griffin \& Allen, 2006; Yeh, 2010). Resilience scholars also noted the importance of extrinsic factors such as protective environments, resources, parental support, adult mentoring, or community organizations (Pérez et al., 2009), and general social support and connection with others (Brown, 2010).

Additionally, our resilience framework utilizes Nicolazzo's (2017) focus on resilience as a practice, not an inherent trait, that recognizes agency and comes from an affirmative standpoint (Nicolazzo, 2017). Although Nicolazzo's (2017) framing of resilience is based on a study about trans* college students, the focus on student agency, evolving practice, and affirmation are relevant to the minoritized students in the current study, as it provides a critical awareness of students' identities and the broader context in which students' experiences are situated. Similarly, the current study's resilience focus is not to place the burden on the student to overcome challenges, but rather to understand how these students navigated higher education after a natural disaster so that postsecondary educators can create systems that foster this resilience and address challenges students faced.

In sum, resilience theory led us to examine how students utilize protective factors, both intrinsic and extrinsic, to actively deal with challenges. Nicolazzo's (2017) conceptualization of resilience allowed us view resilience as a practice, not an inherent trait, which recognizes agency and comes from an affirmative standpoint. The current study's resilience framework shaped the interview protocol to examine how students utilized protective factors in navigating higher education after Hurricane Maria. The resilience framework also guided data analysis and presentation regarding the organization of findings into intrinsic and extrinsic protective factors addressed by participants. Dr. Nicolazzo's framing of resilience provided an additional critical lens to our conceptualization of resilience that guided the study throughout. 


\section{Methodology}

Data for this study is from three individual semi-structured, audio recorded qualitative interviews with Puerto Rican college students directly impacted by 2017 Hurricane Maria. Interviews occurred in spring 2018, and were conducted via Skype/phone, lasted approximately 75 minutes, and consisted of open-ended, semi-structured interview questions. A resilience framework guided the interview protocol to examine the following research questions: How did the 2017 hurricanes impact college students in areas directly hit by the storms? How did college students displaced to the contiguous U.S. demonstrate resilience in navigating the transition to college post-hurricane? How did college students not displaced demonstrate resilience in navigating the transition post-hurricane?

This exploratory qualitative study followed a basic qualitative design (Biddix, 2018; Merriam \& Tisdell, 2016), which "involves using primary methods for data collection and a generalized approach to data analysis" (Biddix, 2018, p. 54). This basic interpretive approach allowed participants to focus on meaning making of their individual experiences (Merriam \& Tisdell, 2016), which aligns with the current study goals of participants sharing how they "make sense of their lives and their experiences” (Merriam \& Tisdell, 2016, p. 24). Our goal of understanding the meaning of participants' experiences as rooted in their voices is also reflected in the key tenets of basic qualitative design which "include eliciting understanding and meaning, the researcher as the primary data collection instrument, use of different field methods, inductive data analysis, and reporting results using rich description" (Biddix, 2018, p. 54).

\section{Participants}

Using purposive sampling (Lincoln \& Guba, 1985) to seek participants with specific characteristics, we invited study participation by emailing university gatekeepers in the contiguous U.S. and at institutions outside of the contiguous U.S. to seek students currently enrolled at institutions of higher education who were directly impacted by Hurricanes Harvey, Irma, and Maria. The principal investigators used Google searches 
to compile a list of over 100 individuals who serve in senior student affairs roles for enrollment management, admissions, and financial aid for institutions directly hit by the 2017 hurricane season, as well as at U.S. institutions of higher education who were in the news for or actively publicized regarding accepting displaced students after the hurricanes. Gatekeepers were provided information about the study and the invitation to participate, including a Google form to express interest in participation that they passed on directly to students who might be eligible for the study. This process resulted in approximately 20 Google forms completed that included demographic information and electronic consent forms, but ultimately yielded three participants who scheduled and completed their individual interviews. Participant demographic information can be found in Appendix A. Although a smaller sample size than initially anticipated, the stories participants shared were rich. The focus on quality of meaningful, detailed analysis from a small number of participants versus seeking a larger sample size aligns with commonly accepted qualitative procedures (Mason, 2010). Also, the authors acknowledge that conducting follow-up interviews would have provided important data, but the grant parameters that enabled this study, including externally imposed timeline and funding limitations, did not allow for follow-up interviews.

Ethical considerations. This study was approved by the researchers' university's Institutional Review Board which ensured that we used safe and ethical practices when engaging with our participants. Furthermore, we carefully crafted questions using a resilience framework to focus upon how our participants navigated college life after Hurricane Maria rather than framing the questions to explore how students were burdened by overcoming obstacles. In the process prior to beginning interviews, participants were made aware that they could pause or quit the interview at any point, and, as interviews were conducted, we were thoughtful in reflecting on participants' experiences. At the conclusion, participants were thanked and were encouraged to reach out to the researchers if they felt they needed further reflection or assistance. 


\section{Data Collection}

The two co-authors conducted three individual semi-structured, audio recorded qualitative interviews with Puerto Rican college students directly impacted by 2017 Hurricane Maria. Interviews occurred in spring of 2018, and were conducted via Skype/phone, lasted approximately 75 minutes, and consisted of open-ended semi-structured interview questions. The interview protocol was informed by the resilience framework and included questions such as the following: How has your college experience been impacted by the hurricanes; what personal characteristics or coping mechanisms do you hold that have helped you during this time; and, what types of support have you had during this time? All participants were asked what suggestions they had for campus educators to better serve students impacted by natural disasters.

\section{Data Analysis}

Transcripts were de-identified, and we hand coded data using the grounded theory coding paradigm with the stages of open, axial, and selective coding to determine the themes related to the primary research questions (Corbin \& Strauss, 1990). This process ultimately followed a collaborative approach to narrative strategies involving moving participant stories into codes and categories, with eventual incorporation of direct participant quotes to highlight key themes (Riessman, 2008).

\section{Research Rigor}

Qualitative rigor and trustworthiness were addressed throughout the research process. We employed memoing, peer debriefing, and member checking. As a research team, the co-authors memoed to make sense of the data and used collaborative intentional reflection to collaborate for consistent coding, provide detailed descriptions, share data that that fell outside of main themes, and clarify bias through attention to reflexivity and positionality (Lincoln \& Guba, 1985; Merriam, 2002). Furthermore, participants were given their de-identified transcripts in order to check for continuity, clarity, and accuracy. They had the opportunity to edit the data to ensure that the transcripts were reflective of their experiences. 
Triangulation strategies also included sharing findings that directly reflect the raw data, including use of direct participant quotes and coauthor collaboration to verify alignment of findings and data (Merriam, 2002). Finally, as a form of reflexivity, the co-authors reflected upon their positionality throughout the data collection and analysis processes.

Researcher positionality. The co-authors are primary instruments of data collection and analysis (Corbin \& Strauss, 1990; Lincoln \& Guba, 1985), and our experiences and identities impact the research process, including interacting with participants and their comfort and disclosure levels with us. Reflecting on our positionality and reflexivity allowed us to understand and address this reality and to think critically about the importance of disrupting the false and damaging notion of desired objectivity in research (Dunbar, Rodriguez, \& Parker, 2002). The principal investigator studies college student learning and development, including minoritized student resilience, has previously co-led hurricane relief work with college students, and has recently chaired a completed dissertation on campus communication during severe weather. However, this topic is not either of the co-authors' primary areas of expertise, but as a current and a future HESA faculty member, they hope that studies such as this one help provide curricular resources for graduate students preparing for their full-time student affairs careers, possibly working directly with students impacted by crises such as natural disasters. Although the co-authors have relatively limited experience on the specific topic of campus crises related to natural disasters, their combined scholarship and research agendas on college student experiences, particularly regarding resilience and minoritized populations, provided a bridge to connecting with participants and honoring their stories related to navigating higher education after the hurricane.

Researcher reflexivity. Some of the principal investigator's most salient identities related to this study are that she is a White, queer woman, and a higher education faculty member who has never been directly impacted by a severe natural disaster. This study's co-author identifies as a White, gay man and currently serves as a graduate assistant and doctoral student in higher education. Both of the authors are from 
the contiguous U.S. and do not speak Spanish. These differences in social identities and life circumstances could potentially create a barrier to developing rapport with participants. However, the authors noted the participants were open regarding asking about the researchers' own education and career, inquiring about their interests in the study, and one participant noted appreciation for opportunities to share her story. There were a few times when the authors clarified a few Spanish words with a participant during the interview. Co-authoring also facilitated reflexivity, as there was a colleague with whom to ask questions, process, and double-check the research process for quality and mindfulness of ethical treatment of participants.

\section{Limitations}

Although the study has a limited number of participants, the intent of a larger qualitative sample is not to produce generalizable data. The suggestions for future research section provides ideas on how to gather additional data that can continue contributing to the scholarly conversation on serving college students impacted by severe natural disaster crisis events. Expanding the sample beyond Puerto Rico would also provide important information on how students from various geographic areas and backgrounds might experience natural disasters differently, calling for context-relevant responses and support when working with students.

\section{Findings}

As reflected in the framework, both intrinsic and extrinsic factors are relevant for understanding resilience. Specifically, participant stories highlighted intrinsic resilience-related factors including mental health and extrinsic resilience-related factors related to community and university logistics.

\section{Mental Health}

Participants discussed their intrinsic factors related to their mental 
health. These included feelings of uncertainty, stress, and boredom. Participants revealed that they often felt uncertain about life both on and off campus following the hurricane. Hadria spoke about the uncertainty of traveling to a new institution in the continental U.S. as she explained, "I got emotional the first week, because I was far away from home...I'm not in my comfort zone or anything. I've always lived in Puerto Rico. I've never known anything else. This is a whole new city to me." Yaya remained in Puerto Rico following the hurricane and was able to stay at her university. She was concerned about course progress without internet, and her class schedules were changed. She remembered, "I was trying to actually pay attention, but I'm so tired physically and mentally. It's like, 'I really hope I don't have an exam in this class because I know I won't pass it."' Despite faculty making accommodations by eliminating tests, Yaya still felt the stress of technology issues and course scheduling changes.

\section{Support}

One of the ways in which participants revealed their extrinsic motivations was through means of support, including the importance of community and institutional support.

Community. The most prevalent means of support was from the participants' communities. Support came from family, friends, and neighbors and was at times educational support, emotional support, monetary support, and even physical/resources support. Alice discussed travelling to the continental U.S. and having a friend help her out with her coursework. Though Alice maintained her enrollment at her university in Puerto Rico, she was able to find resources at a new university through the help of her friend. Hadria discussed finding a community of other Puerto Rican students at her new university in the U.S., with whom she was able to find comfort due to their shared concern over Puerto Rico.

Yaya revealed how monetary support was found in her community, both from her family who could help support her when she was without work, but also by friends who moved in to her apartment and helped with paying rent. Multiple participants also talked about how communities came together to trade and provide physical resources, such as water 
filters, food, and electricity. Hadria remembered, "I barely saw my neighbors before the hurricane, but after the hurricane, I would basically see my neighbors every day, because we were always helping each other out..." and, "It was another way to cope, like having human contact, not staying like a hermit in your house, reaching out to people." Yaya shared Hadria's mentality toward building community, "we did a little community of exchange. We reached out to other people. Like, 'Hey. It's okay. This is hard, but let's keep on going. We can do this."'

Institutional. Participants also revealed the ways their institutions of higher education offered support. Participants believed that universities mostly took a proactive role in helping them be successful. For example, Alice recalled how the university reconvened classes about two weeks after the hurricane but shifted scheduling to accommodate students. Yaya also mentioned how the university not only shifted classes, but also eliminated exams. Alice recalled how her university in Puerto Rico extended the fall semester into January in order to help students stay caught up with their work. Yaya explained how one instructor allowed students to handwrite their work if they did not have access to a computer. She also explained that the professor was less strict with their formatting and citation style as it was not as easy to accomplish by hand. Unfortunately, maintaining studies at Puerto Rican universities proved difficult for the students. Hadria, as she was the only student who fully transitioned to a new university in the contiguous U.S., had a different experience. She remembered, "Honestly, I feel like [transferring] was ... That was a miracle. That's one of the biggest miracles I've ever had in my life." At her new university, she received free housing, meals, and textbooks to ease her transition. Her university also sponsored trips to a local Target to get items for her room in the residence hall. She felt that her university had fully prepared to accept and help Puerto Rican students.

Resources. Participants also spent time reflecting upon the resources offered by their universities. The two students who traveled to the contiguous U.S. in particular discussed this. For example, Hadria shared how her new university covered many costs and provided resources to Puerto Rican students who were displaced by Hurricane Maria. Alice 
also noted the importance of university resources as she continued her studies. Though she continued taking classes from her university in Puerto Rico, she briefly moved to the United States. She found a university in her temporary hometown that allowed her to use the library and its resources for a small, one-time fee of $\$ 50$. She voiced her appreciation for this university, as she then had access to books and documents that she would not have had otherwise.

\section{Challenges}

Participants revealed a number of challenges that affected their extrinsic motivation. These included issues with university logistics such as scheduling, technology, and classroom learning.

University logistics. Our participants shared challenges related to university logistics. Participants revealed that universities in Puerto Rico changed schedules due to Hurricane Maria. Though the changes were meant to help the students, they did not always accomplish this goal. For example, Hadria recalled how her classes in Puerto Rico started almost two months after they were scheduled, which made her feel behind. She also explained that she faced struggles with the logistics of transferring because she found administrators unhelpful. She also felt that the university could have better supported students following Hurricane Maria. She shared, "I feel like they weren't really looking at us as students who had just gone through a hurricane. They were trying to act as if we were just students who were just regular students in regular times." Similarly, once Hadria decided to relocate to a university outside of the islands, she struggled to apply for the program because, "...I had to apply on my phone with the little amount of signal that I had, with no electricity," so, "I got on top of this little gate thing that we have in my house...to get the most signal that I could. That's how I applied."

Logistical challenges extended beyond course schedules and technology to classroom experiences. For example, Hadria faced challenges related to academic rigor after transferring universities. She recalled, "I've never experienced such tough academic learning before in my life. When I got to [University], I was like, 'I feel so dumb here. People 
here are so smart'...It was a big harsh jump from one academic level to another..." However, Hadria also reflected that, "In the end, I'm still really happy that [University] really challenged me with their classes...because I do actually feel like I learned a lot and I'm going to need all that knowledge now over here [in Puerto Rico]." Ultimately, challenges with university logistics led participants to express the need for educators to understand their unique situations, while also acknowledging students' desire to have rigorous learning experiences.

\section{Discussion and Implications}

The following discussion and implications should be considered in light of individual institutional context when seeking to foster supportive environments for students navigating college after natural disasters. Given that one participant remained in Puerto Rico and two participants relocated to the continental U.S., study findings may be of use to educators in various geographic areas. We urge educators to also remain aware of the evolving socio-political climate in which U.S.-Puerto Rico relationships exist. One example tied to tangible resources is the Hurricanes Harvey, Irma and Maria Education Relief Act of 2017, which allows for reallocation of federal funds to institutions enrolling students affected by natural disasters. However, an inequitable distribution of Education Department funds disadvantages island universities (Kreighbaum \& Redden, 2018).

Educators can be aware of these broader circumstances and work to serve students by creating resources that cultivate equitable partnerships between island and continental U.S. institutions. This critical approach also emphasizes the need to view resilience as a practice, not an inherent trait, that recognizes agency and comes from an affirmative standpoint (Nicolazzo, 2017), and as resilience focused on strengths rather than deficits (Pérez et al., 2009). This focus on strengths and healthy development (Pérez et al., 2009), and awareness regarding student agency, evolving practice, and affirmation (Nicolazzo, 2017) also centers understanding student experiences as an avenue for postsecondary educators to support students, rather than tasking individual students to 
overcome challenges in isolation from a broader contextual understanding. Within this broader structural reality, the goal of the current study is to understand how these students navigated higher education after a natural disaster so that postsecondary educators can create systems that foster resilience and address challenges students faced.

Mental health was a main theme that emerged from participant stories, which is a finding reflected in existing literature on college student experiences with natural disasters and the psychological effects (Bromet et al., 2017) such as posttraumatic stress (Waters, 2016). Two studies in particular noted that being displaced after a natural disaster was a key factor in students' psychological well-being (Bromet et al., 2017; Davis, Grills-Taquechel, \& Ollendick, 2010). Similar to these findings, the current study participants noted that displacement in particular led to mental health challenges. Although experiencing PTSD was a finding reflected in related literature (Davis et al., 2010; Waters, 2016), current study participants used mental health language specific to uncertainty, stress, boredom. Uncertainty related to economic concerns, relocating to a new place far from one's comfort zone, potential inability to access technology to complete coursework, and exhaustion causing challenges with focusing in rearranged intensive course schedules. Participants also expressed lingering concern over being prepared for another storm, especially regarding challenges in the broader Puerto Rican circumstances. Participants carried additional stress related to worrying about government instability and a lack of ability to access money in case of future natural disasters. Although tackling this broader context may seem beyond the scope of individual educators' efforts, an awareness of these realities provides opportunities for meaningful dialogue with students seeking support in processing their circumstances. These critical conversations are opportunities to discuss resilience-based strategies with students to help foster student awareness of these practices. Simultaneously, educators can use the conversations to learn more about students' individual experiences, which can guide higher education practice in creating climates that foster resilience. 
In the direct aftermath of the storm, participants also noted strain on their mental wellness due to boredom, including barriers to connections with friends who left classes or who participants could not contact regularly without use of a phone. Participants employed resilience strategies when developing new frameworks for how they viewed spending their time, including newfound enjoyment of being in nature, spending time with family, and playing games. Awareness of these mental wellness concerns and resultant strategies enables institutions of higher education to create conditions that help reduce uncertainty and stress on students. For example, this could include having clear, accessible procedures and contact information to access information about tangible steps in how to proceed with coursework, for both displaced and remaining students. Understanding student needs and motivation for continuing studies after natural disasters is important for creating intentional efforts regarding persistence and retention. Current study participants were determined to continue their studies, and expressed a desire to earn their degree to meet career and educational goals, which were motivational factors also reflected in related literature (Phillips \& Herlihy, 2009). These intrinsic resilience practices reflect resiliencerelated factors such as a sense of purpose and future, and self-efficacy (Bean \& Eaton, 2001; Benard, 1993; Griffin \& Allen, 2006; Yeh, 2010).

Individual practices are also couched within extrinsic resilience factors such as protective environments and resources (Pérez et al., 2009). For example, current study participants reinforced scholarship that relaxing admissions requirements (Coco, 2015) is an important factor in recruiting and retaining displaced students. Flexibility in policies is key, as participants noted the importance of considering individual students' circumstances and making accommodations. For example, students may not have electronic or hard copy access to their academic files, so host institutions should relax admissions standards to accept informal transcripts, test scores, proof of GPA, and other documents like letters of recommendation, while also working with students on financial challenges such as application or transfer fees. Removing logistical barriers will allow for a less stressful and more seamless transition to continuing 
in coursework. This support will also require the work of educators in areas like admissions, registrar, and financial aid. Additionally, academic advisors will need to spend one-on-one time with students to assist with intentional course selection based on each student's home institution program of study.

Student affairs educators in co-curricular involvement areas are important for helping students stay connected to friends or make new connections to bolster a sense of belonging. This purposeful engagement provides stress relieving and peer-connection building opportunities for students. Current student participants reflected existing scholarship on the importance of students forming friendships post-natural disaster, as well as institutions offering support such as counseling (Coco, 2015). Providing proactive outreach regarding mental wellness services through access to free campus counseling is also an important component to serving these students. Similarly, campuses can update comprehensive support efforts to combine post-natural disaster support with proactive disaster preparedness plans. Although current student participants did not highlight any experiences with pre-disaster preparedness, they did express that after experiencing the hurricane, they were worried about being prepared for future natural disasters. Given the clear lack of student disaster preparedness reflected in the related literature (Davis, Weber, Schulenberg, \& Green, 2019; Lee \& Lee, 2019; Lovekamp \& McMahon, 2011; Simms et al., 2013), institutional campus crisis management can include proactive measures to help students increase knowledge and preparedness for natural disasters.

Cultivating support was another main theme in participants' resilience practices, which is also a key aspect reflected in related resilience literature (Brown, 2010; Pérez et al., 2009). Support was found in community including family, friends, and neighbors, and also included educational support, emotional support, monetary support, and physical/ resources support. Participant stories made clear the importance of family, friends, and neighbors as primary, pre-existing community support. Given the challenges to technology and communication, educators have an opportunity to assist students in maintaining connections to their home 
communities, while also supporting conditions for students to form new connections in their host communities. Providing free access to technology ranging from computers and wireless internet to potential use of free long-distance calling services online would provide access to students' home communities depending on the remaining infrastructure post-storm. Although participant circumstances differed between the two studies, Nicolazzo's (2017) study reinforced current study findings that virtual connections are meaningful for students in creating community and finding support. While valuing and facilitating these home-connections, educators can simultaneously provide opportunities for host campus communities such as bringing together all of the relocated students on campus and in the area to connect with one another, while also hosting events for them to socialize and integrate with the host institution's students. Students should be encouraged to be involved in pre-existing campus co-curricular opportunities as a means to form community, while educators also offer special programming and support services for relocated students.

At a university level, it is clear that educators must proactively acknowledge the situation at hand after a natural disaster crisis, and clearly acknowledge individual students and how their educational experiences have been impacted. Participants emphasized that it was harmful for educators to ignore the realities of the situation and to proceed as though everything was normal. Acknowledging the circumstances and reacting accordingly included creating more accommodating logistics such as shifting course scheduling, assisting with financial resources, and allowing library access. Existent literature did not highlight these specific logistics as noted by our participants, but these efforts are similar to Coco's (2015) findings on the importance of relaxing admissions requirements for displaced students. However, participants noted that some of these changes such as extremely long blocks of time for each class, or differing levels of academic rigor between institutions, caused challenges to their academics. Hadria demonstrated intrinsic resilience practices by reframing her situation regarding the increased intensity of her studies at her host institution, as she focused on forming 
new study habits and embracing new knowledge she will use when she returns to Puerto Rico.

In terms of external resilience factors from supporters, many of the accommodations were made by student affairs administrators regarding university procedures, but individual faculty also played important roles in supporting students. Although participants did experience some inflexible faculty members regarding deadlines and procedures, most were supportive. For example, some faculty canceled exams and deemphasized formatting and citations in essays due to students having to hand write assignments versus usually typing on a word processor.

Before individual faculty can work to accommodate and support students in these situations, they have to be aware these students are in their courses. Institutions can consider a notification system that honors academic records privacy while empowering students to connect with individual faculty for support. Although Shaw (2018) focused on preparing future student affairs educators through formal coursework to gain skills regarding campus crisis management, it is clear there is a need for faculty to also undergo some awareness and skills training regarding how to serve students in times of natural disaster. Creating an overall welcoming climate from both student affairs and faculty educators can enhance an important sense of community. Hadria's experience at her host university stood out as a particularly powerful example of how to be accommodating and welcoming to a displaced student. In addition to receiving free housing, meals, and textbooks, the university sponsored trips to a local Target to furnish her residence hall room. Her experience was especially positive at her host institution, and she was very enthusiastic about the potential for permanent transfer there versus graduating from her home institution in Puerto Rico. The proactive university accommodations, plus the strong interpersonal relationships she made there, led to this decision. Hadria's journey is one example of how important it is for educators to understand the needs of relocated students and to create welcoming, accommodating environments. 


\section{Suggestions for Practice}

The current study discussion and implications highlight the importance of student affairs educators in a variety of functional areas collaborating with faculty and the surrounding community to proactively reach out to students impacted by a natural disaster crisis. This proactive approach requires collaboration on campus to notify educators about these students' presence as a starting point to create a comprehensive support network. Convening a group of campus educators in these efforts could streamline forming and advertising a "one stop shop" resource for students that is comprehensive and easily accessible. Forming relationships directly with the students impacted by natural disaster crisis can help educators respond to student support needs that may extend beyond this pre-existing foundational support plan. Similarly, these student relationships can explore understanding student motivation for continuing their studies post-hurricane, such as desire to earn a degree, self-improvement, and meeting career and educational goals (Phillips \& Herlihy, 2009), and additional support can be tailored to supporting students in these motivational factors. Also, it is clear from the current study findings, as well as the literature review, that mental health is a concern for students impacted by natural disasters. As such, these campus resources and student relationships should incorporate accessible, culturally relevant mental health support services that address stress and PTSD (Waters, 2016).

Host institutions may consider pre-planned orientation sessions tailored to displaced students that can be offered at any time in the semester. These orientation sessions can provide many of the typical orientation offerings such as a campus tour and meeting HESA educators, while also sharing resources particularly relevant to these students in their time of transition. Similarly, HESA educators such as academic advisors can be assigned to this student population with the goal of supporting them through retention-related challenges, including addressing logistical concerns for students like our participant Hadria who wished to complete her degree at her host institution due to her positive 
experience there, including the friendships she formed, which was a factor Coco (2015) found in students being retained at host institutions. HESA educators can also assist with student persistence in navigating logistical challenges for students who plan to return home and continue their studies, which Coco (2015) found to be the majority of students within one year of being displaced, especially due to financial reasons or missing family. It may be particularly important for host institutions to take initiative in these efforts, as home institutions directly impacted by the natural disaster may be focused on navigating organizational change and striving for institutional equilibrium, as seen in Shaw's (2016a, 2016b) findings on campus climate management following Gulf Coast hurricanes.

HESA graduate preparation programs can also consider how to facilitate learning around this topic. In addition to offering a crisis management-focused course, such as the one Shaw (2018) found useful for training future student affairs professionals, this topic can be incorporated through HESA curriculum. Also, a key guiding document for graduate students and current professionals is the ACPA/ NASPA competencies (2015). The competencies currently note crisis management in the Organization and Human Resources area, as well as in Advising and Supporting. However, there is an opportunity to build additional professional guidelines and resources for best supporting students impacted by natural disaster crisis. These suggestions should include considerations for serving students relocated from outside of the continental U.S. while also incorporating awareness of social identities and broader circumstances surrounding the situation. Institutions successful in supporting these students could share their experiences and suggestions to supplement student feedback. ACPA is particularly poised for meaningful collaborations with Puerto Rico and surrounding areas, given the existing division of ACPA, the Caribbean Tertiary Level Personnel Association. Similarly, NASPA expanded their regions to include "areas," one of which is the Latin America and Caribbean (LAC) area. The NASPA focus areas do not include a specific crisis response-related group, but ACPA has a Commission for Campus Safety and Emergency Preparedness (CCSEP), which offers a natural starting point for educational leaders 
interested in this topic to contribute knowledge to guide professional development.

\section{Suggestions for Research}

There are opportunities to continue engaging in this work, including further contact with original study participants through a longitudinal study to examine how Hurricane Maria impacted their long-term educational trajectories. Also, expanding the sample size and geographic reach of the study would provide more comprehensive data regarding the 2017 hurricane season, or regarding additional natural disaster crises. Researchers could also interview institutional agents to gain their perspectives on suggestions to proactively support students in natural disaster crisis situations.

\section{Conclusion}

The findings from the current study highlight that student stories can guide student affairs educators in creating conditions which support students in the aftermath of hurricane devastation. These crisis events can extend to other types of natural disasters as well, and will continue to impact college students with the recent increase in weather-related and natural resource disasters. There is a need for continued scholarly conversation on this topic so educators can be prepared to support students in the aftermath of future storms. 
Appendix A. Participant Demographics (Self-Identified)

\begin{tabular}{|c|c|c|c|}
\hline Pseudonym & Alice & Hadria & Yaya \\
\hline Age & 40 & 18 & 24 \\
\hline Gender & Female & Female & Female \\
\hline Race/Ethnicity & Hispanic & Puerta Rican & Latina \\
\hline Major & $\begin{array}{l}\text { PhD } \\
\text { History }\end{array}$ & $\begin{array}{l}\text { Undergrad } \\
\text { Biology }\end{array}$ & $\begin{array}{l}\text { Masters } \\
\text { Archeology }\end{array}$ \\
\hline $\begin{array}{l}\text { Anticipated } \\
\text { Graduation }\end{array}$ & 2020 & 2021 & 2020 \\
\hline $\begin{array}{l}\text { Career/ } \\
\text { Educational Goals } \\
\text { Relocation Status }\end{array}$ & $\begin{array}{l}\text { Advertising; } \\
\text { Research } \\
\text { Florida }\end{array}$ & $\begin{array}{l}\text { Medical } \\
\text { School } \\
\text { Louisiana }\end{array}$ & $\begin{array}{l}\text { PhD Foresnic } \\
\text { Anthropology } \\
\text { Did not relocate }\end{array}$ \\
\hline
\end{tabular}




\section{References}

American College Personnel Association \& National Association of Student Personnel Administrators. (2015). ACPA/NASPA professional competency areas for student affairs educators. Retrieved from http:// www.naspa.org/images/uploads/main/ACPA_NASPA_Professional_ Competencies_FINAL.pdf

Bean, J., \& Eaton, S. B. (2001). The psychology underlying successful retention practices. Journal of College Student Retention, 3(1), 73-89.

Benard, B. (1993). Fostering resiliency in kids. Educational Leadership, 51(3), 44-48.

Biddix, J. P. (2018). Research methods and applications for student affairs. San Francisco, CA: Jossey-Bass.

Bromet, E. J., Atwoli, L., Kawakami, N., Navarro-Mateu, F., Piotrowski, P., King, A. J., ... \& Kessler, R. C. (2017). Post-traumatic stress disorder associated with natural and human-made disasters in the World Mental Health surveys. Psychological Medicine, 47(2), 227241.

Brown, B. (2010). The gifts of imperfection: Let go of who you think you're supposed to be and embrace who you are. Center City, MN: Hazeldon.

Coco, J. C. (2015). Retention of displaced students after hurricanes Katrina and Rita. Journal of College Student Retention: Research, Theory \& Practice, 19(1), 98-111.

Collins, A. B. (2009). Life experiences and resilience in college students: A relationship influenced by hope and mindfulness. (Doctoral Dissertation). Texas A\&M University.

Corbin, J., \& Strauss, A. (1990). Grounded theory research: Procedures, canons and evaluative criteria. Zeitschrift fur Soziologie, 19(6), 418-427.

Davis, T. E., Grills-Taquechel, A. E., \& Ollendick, T. H. (2010). The psychological impact from hurricane Katrina: Effects of displacement and trauma exposure on university students. Behavior Therapy, 41(3), 340-349. 
Davis, C. N., Weber, M. C., Schulenberg, S. E., \& Green, J. J. (2019). University students' disaster preparedness: A focus group study. Best Practices in Mental Health, 15(2), 29-47.

Dunbar, C., Jr., Rodriguez, D., \& Parker, L. (2002). Race, subjectivity and the interview process. In J. Gubrium and J. Holstein (Eds). Handbook of Interview Research: Context and Method (pp. 279-298). Thousand Oaks, CA: Sage.

Griffin, K., \& Allen, W. (2006). Mo' money, mo' problems? High-achieving Black high school students' experiences with resources, racial climate, and resilience. Journal of Negro Education, 75(3), 478-494.

Johnson, D. (2017, September 24). Is this the worst hurricane season ever? Here's how it compares. TIME. Retrieved from http://time. com/4952628/hurricane-season-harveyirma-jose-maria/

Kreighbaum, A., \& Redden, E. (2018). Aid in the wrong direction? Chronicle of Higher Education. Retrieved from https://www.insidehighered. com/news/2018/05/08/critics-question-education-departmentsefforts-help-students-puerto-rico

Lee, E., \& Lee, H. (2019). Disaster awareness and coping: Impact on stress, anxiety, and depression. Perspectives on Psychiatric Care, 55, 311-318. Lincoln, Y. S., \& Guba, E. G. (1985). Naturalistic inquiry. Newbury Park, CA: SAGE Publications, Inc.

Lovekamp, W. E., \& McMahon, S. K. (2011). I have a snickers bar in the trunk of my car: Student narratives of disaster risk, fear, preparedness, and reflections on Union University. International Journal of Emergencies and Disasters, 29(2), 132-148.

Mason, M. (2010). Sample size and saturation in PhD studies using qualitative interviews. Forum: Qualitative Social Research, 11(3). Retrieved from http://www.qualitativeresearch.net/index.php/fqs/ article/view/1428

Merriam, S. B. (2002). Assessing and evaluating qualitative research. In S. Merriam (Ed.) Qualitative research in practice: Examples for discussion and analysis (pp. 18-36). San Francisco, CA: Jossey-Bass. 
Merriam, S. B., \& Tisdell, E. J. (2016). Qualitative research: A guide to design and implementation. San Francisco, CA: Jossey-Bass.

Nicolazzo, Z. (2017). Trans* in college: Transgender students'strategies for navigating campus life and the institutional politics of inclusion. Sterling, VA: Stylus.

Patricola, C. M., \& Wehner, M. F. (2018). Anthropogenic influences on major tropical cyclone events. Nature, 563, 339-356.

Pérez, W., Espinoza, R., Ramos, K., Coronado, H., \& Cortes, R. (2009). Academic resilience among undocumented Latino students. Hispanic Journal of Behavioral Sciences, 31(2), 149-181.

Phillips, T. M., \& Herlihy, B. (2009). Motivational factors underlying college students' decisions to resume their educational pursuits in the aftermath of Hurricane Katrina. Journal of College Counseling, 12(2), 101-112.

Riessman, C. K. (2008). Narrative methods for the human sciences. Los Angeles, CA: Sage.

Santiago, L., \& Schoicet, C. E. (2018, August 26). Puerto Rico's new Hurricane Maria death toll is 46 times higher than the government's previous count. $C N N$. Retrieved from https://www.cnn. com/2018/08/28/health/puerto-rico-gw-report-excess-deaths/ index.html

Shaw, M. D. (2016a). Organizational change as a function of disaster recovery: Lessons from Gulf Coast institutions. College Student Affairs Journal, 34(3), 63-75.

Shaw, M. D. (2016b). Pathways to institutional equilibrium after a campus disaster. Journal of Contingencies and Crisis Management, 25(2), 103-113.

Shaw, M. D. (2018). Teaching campus crisis management through case studies: Moving between theory and practice. Journal of Student Affairs Research and Practice, 55(3), 308-320.

Simms, J. L., Kusenbach, M., \& Tobin, G. A. (2013). Equally unprepared: Assessing the hurricane vulnerability of undergraduate students. Weather, Climate, and Society, 5(3), 233-243.

Waters, M. C. (2016). Life after hurricane Katrina: The resilience in survivors of Katrina (RISK) Project. Sociological Forum, 31, 750-769. 
Waxman, H. C., Gray, J. P., \& Padron, Y. N. (2003). Review of research on educational resilience. Center for Research on Education, Diversity, \& Excellence. Santa Cruz, CA.

Yeh, T. L. (2010). Service-learning and persistence of low-income, firstgeneration college students: An exploratory study. Michigan Journal of Community Service Learning, 50-65. 